\title{
Uncertainty in Contextual Effects on Mobility: An Exploration of Causality
}

\author{
Tim Schwanen \\ Transport Studies Unit \\ School of Geography and the Environment \\ University of Oxford, UK \\ and \\ Human Geography Unit \\ School of Business, Economics and Law \\ University of Gothenburg, Sweden \\ Address for correspondence: \\ South Parks Road \\ Oxford, OX1 3QY \\ United Kingdom \\ E-mail: tim.schwanen@ouce.ox.ac.uk
}

Accepted for publication in:

Annals of the American Association of Geographers

Forum on Context and Uncertainty in Geography and GIScience

19 March 2018 


\title{
Uncertainty in Contextual Effects on Mobility: An Exploration of Causality
}

\begin{abstract}
While various forms of uncertainty have been examined in studies of how geographical contexts influence mobility in recent years, this essay argues that greater attention be paid to those types that cannot be tackled automatically with better data or analysis techniques. Using cycling adoption and levels as example, it reflects on some of the uncertainties resulting from reliance in empirical research on the assumption of causality as regularity in conjunction between dependent and independent variables. It suggests that working with other understandings of causality can begin to shed light on difficult-to-detect forms of ignorance and generate more dynamic and precise insights into how contexts condition and shape behaviors and spatial practices.
\end{abstract}

Keywords: uncertainty, geographical context, causality, mobility, cycling

Uncertainty has become a major topic in geographical research on everyday mobility over the past decade or so. With the increased deployment of GPS tracking data collected through smartphones and other mobile devices, concerns over positional accuracy and the accurate extraction of activity locations have become prominent (e.g. Huang and Wong 2015; Wan et al. 2017). The use of Global Positioning System (GPS) data as well as big data has also made it easier to tackle what Kwan (2012) has termed the Uncertain Geographic Context Problem (UGCoP). This problem results from lack of knowledge about the true spatiotemporal contexts that exert influence on individuals' behavior or behavioral outcomes. As a result, the use of attributes of people's residential location to understand variations in their levels of, say, physical activity may be flawed if they spend much of their time away from that location in other environments. UGCoP is qualitatively different from the more familiar Modifiable Areal Unit Problem (MAUP), which is also increasingly addressed in studies of everyday mobility (e.g. Horner and Murray 2002; Mitra and Buliung 2012; Tribby et al. 2014), given 
that MAUP and its cousin the Modifiable Temporal Unit Problem (MTUD) (Cheng and Adepeju 2014) derive from the imposition of an arbitrary classificatory grid onto space and time. Yet another type of uncertainty that has received some attention is the recognition that the conjunction between a dependent variable and one or more independent variables may vary across individuals and space. This is what has been explored and addressed through such techniques as multilevel regression analysis (e.g. Schwanen et al. 2004; Elldér 2014) and spatial statistics (e.g. Páez 2006; Cardozo et al. 2012).

Despite many differences, these ways of dealing with uncertainty share two characteristics. They tend to frame and address uncertainty as a problem to be reduced if and where possible. This approach reflects that “[p]erfect knowledge is one of humanity's oldest ideals” (Couclelis 2003: 166) which is deeply entrenched in Western culture (Smithson 2008). This certainly is a productive approach as it lets research activity proliferate, triggers new research questions, and generates substantive insights into how physical, social, and other contexts help to shape mobility behavior or practices. In addition, the literature on geographical research on everyday mobility tends to focus on what Fusco et al. (2017), after Curran (2002), call "measurement uncertainty" and easier-to-tackle forms of "understanding uncertainty". The former relates to the accuracy of spatial data, the latter to the confidence analysts can have in their explanations. In diverse ways, Couclelis (2003) and Fusco et al. (2017) suggest that Geography and GIScience research concerned with uncertainty should pay greater attention to those forms of (understanding) uncertainty that cannot be addressed with better or differently handled data because they emerge from reasoning and assumptions in knowledge production processes. 
In this essay I heed the suggestions by Couclelis (2003) and Fusco et al. (2017) to explore how assumptions regarding causality create a rather challenging variety of understanding uncertainty - unknown unknowns or meta-ignorance - in research on the effects of geographical contexts on everyday mobility. The unknown unknown is a concept popularized by former U.S. Secretary of Defense Donald Rumsfeld but refers to a much earlier recognized situation of "meta-ignorance” (Smithson 2008: 16) in which limits to knowledge and ignorance are not recognized. This type of understanding uncertainty can have multiple origins, including a lack of due reflection on common philosophical assumptions, or methodological practices within a given epistemic community.

Below I address the question of how the adoption of cycling is affected by individuals' context to illustrate some broader arguments about how assumptions about the nature of causality can generate complex amalgams of certainty and uncertainty in knowledge about everyday mobility. In so doing I complement the focus of Couclelis (2003) and Fusco et al. (2017) on epistemology with greater emphasis on questions of ontology.

\section{What Makes People Cycle?}

There is now a vibrant and heterogeneous literature in Geography as well as in transportation, urban planning and public health research on the question what makes people adopt cycling for everyday mobility. Providing even a cursory overview is beyond this essay (but see Heinen et al. 2009; Spinney 2009; Pucher et al. 2010; Corcoran and Li 2014; Buehler and Dill 2016; Götschi et al. 2016; Wang et al. 2016). The literature is highly diversified in terms of theory and methodology, but it is fair to say that most studies rely on quantitative data 
from secondary sources (e.g. government surveys, big data) or primary sources (e.g. selfcollected questionnaire and GPS data). Often these data are analyzed using econometric techniques, including regression and logit modelling. Such an approach generates compelling insights into how cycling adoption and usage is influenced by many different aspect of the geographical context, including physical infrastructure, built environment, individuals' upbringing and life history, the distribution of their activities in space and time, the internalization of wider discourses about cycling, weather and climate, and so forth. Most studies also carefully distinguish between correlation and causation, suggesting that findings do not necessarily reveal causality because of the research design that has been deployed. Two of the most widely recognized limitations are use of cross-sectional rather than longitudinal data and absence of information on potentially critical variables.

\section{Questioning Causality}

Implied here is a specific definition of causality which is premised on regularity in conjunction, and goes back to Hume (1985[1739]): if variations in a (prior event or temporary state) $x$ are conjoined with those in a (posterior and isolated event or separate state) $y, x$ is said to be the cause of $y$. That prior state is often directly observed but is sometimes taken to be unobservable, as when latent class models are used to identify types of individuals or neighborhoods with distinctive propensities to cycle that do not map directly onto observed variables (e.g. Kemperman and Timmermans 2009; McDonald et al. 2012; Oliva et al. 2018). Moreover, the prior event or temporary state can be mental or embodied in nature, and thus include reasons, attitudes, or perceptions. Some of those may be expectations about the future, as when people start to cycle or cycle more often $\left(t_{0}\right)$ because they have come to believe $\left(t_{-1}\right)$ that this will make them fitter or have environmental benefits in the 
future $\left(t_{n}\right)$. This is the logic that tends to undergird studies probing the role of attitudes and motivations in modifications to cycling and other mobility practices (e.g. Chatterjee et al. 2013; Willis et al. 2015).

The definition of causality in terms of regularity of conjunction is so black-boxed that it is only rarely reflected upon in the (quantitative) literature on contextual influences on cycling. However, it is only one way in which causality can be understood; a wide variety of alternatives is on offer. Perhaps the most widely known in Geography is that by critical realism in which the emphasis is on necessity and tendency (Bhaskar 1975; Sayer 2000). As Rutzou (2017) explains, for Bhaskar scientists should not focus on conjunctions of events but on the powers, liabilities and tendencies that objects possess and that make them behave in certain ways. Objects necessarily express themselves in particular ways under the right circumstances, but when part of open systems - as they usually are - they only express themselves tendentially due to the interference of other objects and mechanisms. In research terms, Bhaskar's ontology proposes that researchers distinguish and identify necessary conditions - so-called real causes - for the enactment of a certain effect and enabling factors that are contingent upon space and time. Bhaskar's ideas have direct consequences for understanding cycling adoption and usage, and raise interesting questions. For instance, is having access to segregated bike lanes a real cause whose effect is refracted by interfering objects, or is it rather an enabling factor that reinforces the effects of genuine real causes such as, say, possessing the competency and confidence to cycle in different kinds of traffic? And to what extent is having access to segregated bike lanes a real cause in some places or for certain groups but not in or for others? 
The point here is not to advocate reliance on a specific understanding of causality. Critical realism's approach to causality can easily be criticized, for instance because it privileges structures and stability over difference and change (Rutzou 2017). The latter are valorized in understandings of causality inspired by process thinkers such as Gilles Deleuze, for whom regularity and stability are at best contingent, place and time specific, and the outcome of interactions within and between heterogeneous and differentiating events (ibid.; Deleuze, 1994). While further elaboration of these ideas is beyond the current essay, they do highlight that stable categories and similarity can also be considered achievements that need to be explained rather than givens that can be mobilized as explanations.

Not all process thinkers are as radical as Deleuze was. Alfred North Whitehead, for instance, offered a less extreme notion of causality. Stripped of their precise and technical vocabulary, his writings propose that the world and everything it, including human beings, consist of evolving sequences of events in which orders, identities, traits and qualities are passed on over time in non-deterministic fashion (Whitehead 1929, 1933, 1938). For whatever entity is under consideration - be it a human, an animal, a plant or even a bike or street - "existence is activity ever merging into the future” (Whitehead 1938: 232): each moment $t_{0}$ is a transition in which that entity's own past plus the concurrent environment is synthesized and turned into a set of inputs for synthesizing events at $t_{1}$. In most situations what is transmitted remains more or less the same, but especially with human beings as coordinated streams of events there is always the possibility of new elements from one's environment, which is itself a continuous flow of events, to be incorporated into the ongoing process of sequential synthesis. For Whitehead the "psyche [was] never disembodied and the body [...] never deworlded” (Stenner 2008: 106), with demarcations between a person's body, mind and environment being "vague in the extreme” (Whitehead 1938: 221), a position that resembles 
thinking on embodiment in feminist geography and non-representational theory in various ways (e.g. Longhurst 2001; Thrift 2008; Simonsen 2013). All of this leads to an understanding of causality - and formation of the human being - that is both immanent and open-ended. Against the understanding of regular conjunction between an isolated $x$ and $y$, Whitehead proposed that a person's immediate past plus their environment are actively involved in their ongoing evolution at any point in time yet also that stability of traits, dispositions and other qualities over time can never be assumed.

\section{Implications of a Processual Approach}

This Whiteheadian understanding of causality is only one among many and I neither contend it is superior to others nor suggest it should displace others. It does, however, raise three sets of issues regarding uncertainty in studies of contextual influences on cycling and mobility more generally.

First, alongside the critical realist and Deleuzian understandings, it highlights that there are plausible alternatives to the black-boxed notion of causality as regularity in conjunction in the vast majority of studies into contextual influences on cycling and other forms of mobility. Upon reflection there are surprisingly few substantive arguments for privileging that blackboxed version over others. Its dominance seems to reflect convention, which facilitates relating one's research to that by others, and convenience: not only is a large set of (statistical and econometric) analysis tools available, it also tends to be less demanding to offer evidence supporting the existence of regularity in conjunction than for alternative understandings of causality. However, this is also where meta-ignorance or an unknown unknown becomes a realistic possibility. For what under causality as regularity in conjunction seems a certain 
cause of cycling adoption - say, easy access to high quality cycle lanes, a strong belief that cycling is the most time-efficient way of reaching a destination, or receiving cycling training as part of the primary school curriculum - may not be qualified as such under a different ontological framework. Remaining within the comfort of the conventional understanding of causality may therefore generate an internally valid explanation but paradoxically also create uncertainties that may not be detected. This is in itself no reason to reject that understanding yet suggests that experimentation with different understandings of causality in research can generate further insights into the role that particular contextual conditions and events play in cycling adoption and usage levels.

Second, relying on a Whiteheadian notion of causality in studies of contextual influences on cycling adoption is an effective strategy for drawing attention to possible unknown unknowns. This is because of its "resolute focus on the concrete" (Halewood and Michael 2008: 47) - that is, on how a coordinated set of events such as an individual at $t_{0}$ emerges out of its environment and its own past at $t_{-1}$. This means that, contra customs in mobility biography research (Müggenburg et al. 2015), establishing a conjunction between whether a person cycles, how much when and where at a particulate moment in their life-course (e.g. when attending university) and events or episodes at earlier times (e.g. having been encouraged to cycle to primary school independently by parents/care-givers) is not sufficient to suggest a causal relationship. Analysts will have to demonstrate that an uninterrupted connection through continuous transmission across the stream of events that constitute an individual's life is plausible. While this is not without challenges, one way of suggesting uninterrupted transmission would be to look for intervening events that may have qualified, refracted or superseded the effects of, say, cycling to school independently at a young age. Different methods could be used for exploring uninterrupted transmission, including the co- 
construction of a life history by participant and researcher over one or more resource encounters for a range of participants selected through theoretical sampling (the details of which would depend on the specific aims and objectives of the study that is conducted). Nonetheless, a key challenge would be the identification of how non-conscious experiences and effects of the body-mind's entanglement in the world become part of the ongoing process of sequential synthesis.

Another implication of a resolute focus on the concrete is the imperative to avoid the 'fallacy of misplaced concreteness' (Whitehead 1925) - the substitution of an abstract belief or construct for the concrete events of which the world exists such that those events are obscured rather than rendered understandable. Whitehead was not against abstraction in thought as such, maintaining it was creative and inevitable but needed to be well-founded. As I have explained elsewhere (Schwanen 2015), a Whiteheadian approach to understanding contextual influences on cycling adoption or levels entails the rejection of conditions such as the 3Ds of density, diversity and design (Cervero and Kockelman 1997) of the residential or workplace neighborhood or accessibility - all of which are widely used in the multidisciplinary literature on the effects of the built environment on people's travel-activity behavior - as causes of cycling usage. This claim may be controversial to researchers socialized into that literature but reflects that (static) measure of those conditions fail to capture adequately the stream of interrelated material, affective, discursive and other events that constitute the world in which cycling may take place. The use of abstract universal measures such as the 3Ds also enlarges the epistemological fissure between the contextual experiences of single or intertwined individuals and systematic differences in cycling and other kinds of mobility observed at the level of populations, thereby entrenching the 
micro/macro and singular/plural dualisms in research on contextual influences on everyday mobility.

Now, a Whiteheadian process ontology and the (diffuse) ontologies undergirding much research into contextual influences on cycling are not readily commensurable, but the former once more raises the prospect of unknown unknowns existing in much cycling research. At a minimum, it should invite researchers who are keen to understand what encourages cycling to experiment with more dynamic measures of how embodiment as a (non-)cyclist unfolds in relation to and as part of the world. This can be done in diverse ways, for instance by using ethnographic techniques, virtual reality methods and/or with big data. Opportunities to deploy the last two options will increase rapidly in the coming years, but some of the potential that new data offer can already be gleaned from studies such as that by Helbich and colleagues (2016). To explain variations in Dutch children's transport mode usage for home-to-school trips, these authors relied on detailed - albeit largely static - measures of traffic safety, near real-time weather information and a suite of other indicators. The statistical explanatory power of the dynamics traffic safety and weather variables turned out to be limited in that particular study, but the research does offer a glimpse of the level of precision with which quantitative measures of mobile embodiment within a dynamic urban fabric will become available. Big data in particular might be able to contribute to reduced unknown unknowns given the promise of more accurate information about what happens when and where and because they capture what people do or think more directly than surveys do. However, the algorithmic uncertainties (Kwan 2016) and the ethical dilemmas these capabilities raise (Stephen-Davidowitz 2017) should temper optimism about the extent to which big data can reduce both understanding and measurement uncertainties in research on contextual influences on everyday mobility. 
Finally, a Whiteheadian approach to causality demands an ethos of modesty, irrespective of what big data will make possible. This is because Whitehead's process ontology foregrounds that potentiality and thus the possibility of disruption in seemingly stable traits, dispositions and other qualities should always be entertained: futures are always open and things can always become otherwise. On one level this statement is a platitude but on another it is profound, because Whiteheadian thinking highlights that uncertainty is not merely epistemological but ontological. This throws into doubt the ability to extrapolate - no matter how almost-perfect information is available about how (non-)cycling body-minds have been worlded - and offers a useful counterpoint to the sometimes hubristic claims about how the data revolution marks a fundamental and irrevocable change in capabilities to predict and minimize uncertainty in knowledge.

\section{Conclusions}

Greater attention should be paid to challenging forms of uncertainty, for which better data or analysis techniques are no panacea, in research on contextual influences on everyday mobility. Using the example of cycling, this essay has suggested that understandings of causality - and especially the dominant version of regularity in conjunction between an isolated $x$ and $y$ - have paradoxically performative effects. On the one hand the dominant understanding makes internally valid explanations possible, but on the other its liberal character means that difficult-to-detect forms of 'understanding uncertainty' may be generated. In addition, the dominant understanding also places less emphasis on ontological 
uncertainty in the world and events themselves rather than our knowledge of them than other versions of causality, including the Whiteheadian discussed above.

Perhaps arguing for alternative understandings of causality is swimming against the tide of convention and convenience, but this is a risk worth taking for two reasons. One is that forms of ignorance produced by research into contextual influences on cycling and many other forms of behavior and spatial practice become thinkable. Their enigmatic qualities may not be demonstrated directly backed up by evidence, but it will become easier to speculate about their likely effects on knowledge about contextual influences. This will also enable further elaboration of the reflections on methodological practice offered in this short essay.

Second, experimentation with different understandings of causality will trigger new, more precise expectations and hypotheses about how present and past geographical contexts condition and shape behavior and spatial practice. Above I already offered some examples when discussing whether access to segregated bike lanes can be considered a real cause within critical realism and what intervening events might have affected the transmission across the life-course of the causal influence of cycling to school independently at a young age. Clearly these expectations should be both deepened and generalized to other types of behavior and spatial practice. It is fortuitous that new quantitative data from sensors in Internet of Things applications (smartphones, bike sharing schemes, street furniture, etcetera) offer novel opportunities to put those expectations and hypotheses to the test. In addition to new insight into the dynamic interactions among behaviors, modes of embodiment and their worlds across different time scales, the combination of new expectations and data may also generate recommendations for policy-makers and other interveners that are dynamic, precise, concrete and duly respectful of ontological uncertainty. 


\section{Acknowledgments}

Part of this essay was written during time spent at the University of Gothenburg in Sweden. Comments of two reviewers on an earlier version of the manuscript are gratefully acknowledged.

\section{References}

Bhaskar, R. (1975) A Realist Theory of Science. London: Routledge.

Buehler, R., and J. Dill (2916) Bikeway networks: A review of effects on cycling. Transport Reviews 36 (1): 9-27.

Cardozo, O. D., J. C. García-Palomares, and J. Gutiérrez (2012) Application of geographically weighted regression to the direct forecasting of transit ridership at station-level. Applied Geography 34: $548-558$.

Cervero, R., and Kockelman, K. (1997) Travel demand and the 3Ds: Density, diversity, and design. Transportation Research Part D: Transport and Environment 2 (3): 199-219.

Chatterjee, K., Sherwin, H., and Jain, J. (2013) Triggers for changes in cycling: The role of life events and modifications to the external environment. Journal of Transport Geography 30: 183-193.

Cheng, T., and M. Adepeju (2014) Modifiable temporal unit problem (MTUP) and its effect on spacetime cluster detection. PLOS ONE 9 (6): e100465.

Corcoran, J., and T. Li (2014) Spatial analytical approaches in public bicycle sharing programs. Journal of Transport Geography 41: 268-271.

Coucelis, H. (2003) The certainty of uncertainty: GIS and the limits of geographic knowledge. Transactions in GIS 7 (3): 165-175.

Curran, P. (2002) Forward with uncertainty. In Uncertainty in Remote Sensing and GIS, ed. G. Foody, and P. Atkinson, xi-xvi. Chichester: John Wiley and Sons.

Deleuze, G. (1994) Difference and Repetition. New York: Columbia University Press. 
Elldér, E. (2014) Commuting choices and residential built environments in Sweden, 1990-2010: A multilevel analysis. Urban Geography 35 (5): 715-734.

Fusco, G., M. Caglioni, K. Emsellem, M. Merad, D. Moreno, and C. Coiron-Canicio (2017) Questions of uncertainty in geography. Environment and Planning A 49 (10): 2261-2280.

Götschi, T., J. Garrard, and B. Giles-Corti (2016) Cycling as a part of daily life: A review of health perspectives. Transport Reviews 36 (1): 45-71.

Halewood, M, and M. Michael (2008) Being a sociologist and becoming a Whiteheadian: Toward a concrescent methodology. Theory, Culture \& Society 25 (4): 31-56.

Helbich, M., M. J. Zeylmans van Emmichoven b, M. J. Dijst, M.-P. Kwan, F. H. Pierik, and S. I. de Vries (2016) Natural and built environmental exposures on children's active school travel: A Dutch global positioning system-based cross-sectional study. Health and Place 59: 101-109.

Heinen, E., K. Maat, and B. van Wee (2009) Commuting by bicycle: An overview of the literature. Transport Reviews 30 (1): 59-96.

Horner, M. W., and A. T. Murray (2002) Excess commuting and the modifiable areal unit problem. Urban Studies 39 (1): 131-139.

Hume, D. (1985[1739]) A Treatise of Human Nature. London: Penguin Classics.

Kemperman, A., and H. Timmermans (2009) Influences of built environment on walking and cycling by latent segments of aging population. Transportation Research Record: Journal of the Transportation Research Board 2134: 1-9.

Kwan, M.-P. (2016) Algorithmic geographies: Big data, algorithmic uncertainty, and the production of geographic knowledge. Annals of the American Association of Geographers 106 (2): 274-282.

(2012) The uncertain geographic context problem. Annals of the Association of American Geographers 102 (5): 958-968.

Longhurst, R. (2001) Bodies: Fluid Boundaries. London: Routledge.

McDonald, K., M. Hearst, K. Farbakhsh, C. Patnode, A. Forsyth, J. Sirard, and L. Lytle (2012) Adolescent physical activity and the built environment: A latent class analysis approach. Health and Place 18 (2): 191-198.

Mitra, R., and R. N. Buliung (2012) Built environment correlates of active school transportation: Neighborhood and the modifiable areal unit problem. Journal of Transport Geography 30 (1): 51-61.

Müggenburg, H., A. Busch-Geertsema, and M. Lanzendorf (2015) Mobility biographies: A review of achievements and challenges of the mobility biographies approach and a framework for further research. Journal of Transport Geography 46: 151-163.

Oliva, I., P. Galilea, and R. Hurtubia (2018) Identifying cycling-inducing neighborhoods: A latent class approach. International Journal of Sustainable Transportation, DOI: 10.1080/15568318.2018.1431822.

Páez, A. (2006) Exploring contextual variations in land use and transport analysis using a probit model with geographical weights. Journal of Transport Geography 14 (3): 167-176. 
Pucher, J., J. Dill, and S. Handy (2010) Infrastructure, programs, and policies to increase bicycling: An international review. Preventive Medicine 50: S106-S125.

Huang Q., and Wong D. (2015) Modeling and visualizing regular human mobility patterns with uncertainty: An example using twitter data. Annals of the Association of American Geographers 105 (6): 1179-1197.

Rutzou (2017) Finding Bhaskar in all the wrong places? Causation, process, and structure in Bhaskar and Deleuze. Journal of the Theory of Social Behaviour 47 (4): 402-417.

Sayer, A. (2000) Realism and Social Science. London: Sage.

Schwanen, T. (2015) Understanding process: Can transport research come to terms with temporality? In International Handbook on Transport and Development, ed. R. Hickman, D. Bonilla, M. Givoni, and D. Banister, 660-674. Cheltenham: Edward Elgar.

Schwanen, T., F. M. Dieleman, and M. Dijst (2004) The impact of metropolitan structure on commute behavior in the Netherlands: A multilevel approach. Growth and Change 35 (3): 304-333.

Simonsen, K. (2013) In quest of a new humanism: Embodiment, experience and phenomenology as critical geography. Progress in Human Geography 37 (1): 10-26.

Smithson, M. (2008) The many faces and masks of uncertainty. In Uncertainty and Risk: Multidisciplinary Perspectives, ed. G. Bammer, and M. Smithson, 13-26. London: Earthscan.

Spinney, J. (2009) Cycling the city: Movement, meaning and method. Geography Compass 3 (2): 817-835.

Stenner, P. (2008) A.N. Whitehead and subjectivity. Subjectivity 22: 99-109.

Stephens-Davidowitz, S. (2017) Everybody Lies: Big Data, New Data, and What the Internet Can Tell Us About Who We Really Are. New York: HarperCollins.

Thrift, N. (2008) Non-Representational Theory: Space, Politics, Affect. Abingdon: Routledge.

Tribby, C. P., H. J. Miller, B. B. Brown, C. M. Werner, and K. R. Smith (2016) Assessing built environment walkability using activity-space summary measures. Journal of Transport and Land Use 9 (1): 187-207.

Wan, N., G. L. Kan, and G. Wilson (2917) Addressing location uncertainties in GPS-based activity monitoring: A methodological framework. Transactions in GIS 21: 761-781.

Wang, Y., C. K. Chau, W. Y. Ng, and T. M. Leung (2016) A review on the effects of physical built environment attributes on enhancing walking and cycling activity levels within residential neighborhoods. Cities 50: 1-15.

Whitehead, A. N. (1938) Mode of Thought. New York: Macmillan.

Whitehead, A. N. (1933) Adventures of Ideas. New York: Macmillan.

Whitehead, A. N. (1929) Process and Reality: An Essay in Cosmology. New York: Macmillan.

Whitehead, A. N. (1925) Science and the Modern World. New York: Macmillan. 
Willis, D. P., K. Manaugh, and A. El-Geneidy (2015) Cycling under influence: Summarizing the influence of perceptions, attitudes, habits, and social environments on cycling for transportation. International Journal of Sustainable Transportation 9 (8): 565-579.

TIM SCHWANEN is Associate Professor of Transport Studies and Director of the Transport Studies Unit in the School of Geography and Environment at the University of Oxford, OX1 3QY, United Kingdom. E-mail: tim.schwanen@ouce.ox.ac.uk. He is also a Visiting Professor of Human Geography at the School of Business, Economics and Law of the University of Gothenburg, SE 405 30, Sweden (2016-2019). His research interests include the everyday mobilities of people, goods, and information; cities; transitions towards low-carbon living; inequality and justice; and well-being. 